\title{
Persistence of marrow stromal cells implanted into acutely infarcted myocardium: Observations in a xenotransplant model
}

Derek J. MacDonald, MD, Jun Luo, MD, Takayuki Saito, MD, PhD, Minh Duong, BSc, Pierre-Luc Bernier, MD, Ray C. J. Chiu, MD, PhD, and Dominique Shum-Tim, MD

From the Division of Cardiothoracic Surgery, McGill University Health Center, Montreal, Quebec, Canada.

Received for publication April 12, 2004; revisions received March 5, 2005; accepted for publication April 1, 2005.

Address for reprints: Dominique Shum-Tim, MD, Division of Cardiothoracic Surgery, The Montreal General Hospital, MUHC, 1650 Cedar Ave, Suite L9-513, Montreal, Quebec, H3G 1A4, Canada (E-mail: Dominique. Shum-Tim@muhc.mcgill.ca).

J Thorac Cardiovasc Surg 2005;130:1114-21 $0022-5223 / \$ 30.00$

Copyright (C) 2005 by The American Association for Thoracic Surgery

doi:10.1016/j.jtcvs.2005.04.033
Objective: It has been reported that unmatched adult bone marrow stromal cells could be tolerated by immune-competent allotransplant or xenotransplant recipients under various conditions. This study examined whether xenogeneic bone marrow stromal cells implanted immediately after myocardial infarction can survive and differentiate, attenuating deterioration in left ventricular function.

Methods: In groups I and II $(\mathrm{n}=34)$, myocardial infarctions were created in immunocompetent adult Lewis rats by proximal left coronary artery ligation. In group I, $3 \times 10^{6}$ lacZ-labeled mouse bone marrow stromal cells were immediately injected into the peri-infarct area of the left ventricle, whereas in group II, only culture medium was injected. There were 10 early and 4 late deaths. At 4 weeks after injection, hearts were stained for $\beta$-galactosidase and troponin IC. In groups IIIA and IIIB, lacZ-labeled mouse skin fibroblasts were implanted into rat myocardium $(\mathrm{n}=10$ each) with and without left coronary artery ligation, respectively, and the rats were killed serially. In group IV, animals underwent sham surgery $(\mathrm{n}=5$, no deaths). At 4 weeks, surviving rats in groups I, II, and IV $(\mathrm{n}=10, \mathrm{n}=10$, and $\mathrm{n}=5$, respectively) underwent blinded transthoracic echocardiography for ventricular function studies.

Results: In group I, labeled mouse-derived bone marrow stromal cells were found within rat myocardium that stained positively for troponin IC 4 weeks after implantation. Functionally, mean left ventricular ejection fraction $(P=.007)$, stroke volume $(P=.03)$, and fractional shortening $(P=.02)$ were all significantly higher in group I than in group II. In groups IIIA and IIIB, mouse fibroblasts induced cellular infiltration with rapid loss of donor cells. No labeled cells were found after 4 days. In group IV, there was no change in cardiac function.

Conclusion: Xenogeneic bone marrow stromal cells implanted into acutely ischemic myocardium induced by coronary artery ligation were immunologically tolerated, survived and differentiated, resulting in a cardiac chimera which improved left ventricular function. This unique immunologic tolerance may suggest the feasibility of using bone marrow stromal cells as universal donor cells.

B one marrow stromal cells (MSCs) contain multipotent adult stem cells capable of differentiation into both mesenchymal and nonmesenchymal lineages. ${ }^{1-6}$ When injected directly into the myocardium, subpopulations of MSCs have been shown to incorporate themselves into the host myocardium and differentiate into cardiomyocytes. ${ }^{7}$ There is a growing body of evidence that MSCs possess unique immune modulatory capabilities. ${ }^{8}$ Liechty and colleagues ${ }^{9}$ have demonstrated that human MSCs could engraft in fetal sheep after intraperitoneal implantation, even after the development of immune competence. 
These cells have been shown to persist for as long as 13 months in host tissues without the use of immunosuppression. Recently, our group has reported that xenogeneic MSCs injected intravenously into adult rodents could be recruited and engraft damaged myocardium and survive in the absence of immunosuppression, forming a cardiac chimera. ${ }^{10}$ However, whether such transplanted xenogenic MSCs might survive in the microenvironment of acute myocardial infarction to differentiate and affect left ventricular (LV) performance has not been investigated. In this study, we sought answers to these questions and further documented the unique nature of MSC immune tolerance by comparing the responses between MSCs and differentiated fibroblasts when both were used as xenogeneic donor cells.

\section{Material and Methods \\ Animals}

Female C57B1/6 mice and male Lewis rats were used in this study as the donors and recipients, respectively. All animals received humane care in compliance with the "Guide for the Care and Use of Laboratory Animals" (http://www.nap.edu/ catalog/5140.html) and the "Guide to the Care and Use of Experimental Animals" of the Canadian Council on Animal Care.

\section{Experimental Design}

A total of 34 rats underwent open-chest coronary artery ligations, and the animals were randomly assigned at the time of operation. In group I, labeled mouse MSCs $\left(3 \times 10^{6}\right)$ were injected directly into the peri-ischemic region of rat myocardium 15 minutes after ligation of the proximal left coronary artery. In group II, a similar volume of culture medium was injected into control animals after coronary ligation. Four weeks after injection, all surviving animals underwent blinded in vivo functional assessment with transthoracic echocardiography. On the following day, the animals were killed, and the heart specimens were processed for immunohistochemical studies.

Additionally, in group III $(\mathrm{n}=20)$, the rats had differentiated mature adult cells $\left(3 \times 10^{6}\right.$ labeled female C57B1/6 mouse skin fibroblasts) injected directly into the myocardium. In group IIIA $(\mathrm{n}=10)$, rats received mouse fibroblast implantation into the peri-ischemic region after coronary artery ligation, as in groups I and II, whereas in group IIIB $(\mathrm{n}=10)$, similar fibroblast implantation was carried out without coronary ligation. These animals served as immunologic controls with and without associated myocardial ischemic injury. They were killed serially during a 4-week period, and the hearts were examined for the presence of cellular infiltration and surviving labeled fibroblasts. Finally, in group IV $(n=5)$, the animals underwent a sham operation, thoracotomy without coronary ligation or myocardial injection, with subsequent transthoracic echocardiography at 4 weeks.

\section{MSC Isolation and Labeling}

Bone marrow cells were harvested from female C57Bl/6 mice by flushing the femurs and tibias with Dulbecco Modified Eagle Medium supplemented with $10 \%$ fetal bovine serum and 50 $\mathrm{U} / \mathrm{mL}$ penicillin-streptomycin according to the method described by Wakitani and associates. ${ }^{4}$ Whole marrow was plated in tissue culture dishes, and 5 to 7 days later nonadherent hematopoietic cells were discarded and adherent bone MSCs were cultured at $37^{\circ} \mathrm{C}$ with $5 \%$ carbon dioxide. The lacZ reporter gene was transfected into MSCs with pMFG-lacZ retrovirus-mediated gene transfection, as described previously. ${ }^{11}$ The resulting MSCs expressing lac $Z$ were expanded for 4 weeks before transplantation.

To confirm that the MSCs had been properly labeled, these cells were stained with 5 -bromo-4-chloro-3-indoyl- $\beta$-D-galactoside (Xgal) for detection of $\beta$-galactosidase activity. Cells plated in a $35-\mathrm{mm}$ dish were fixed in $1 \%$ glutaraldehyde for 5 minutes at room temperature and subsequently were washed with phosphate-buffered saline solution. Staining solution at $\mathrm{pH}$ of 7.8 to $8.0,{ }^{10}$ which contained $1-\mathrm{mg} / \mathrm{mL} \mathrm{Xgal,} 1-\mathrm{mmol} / \mathrm{L}$ ethyleneglycol-bis $(\beta$-aminoethyl-ether)-N,N'-tetraacetic acid,

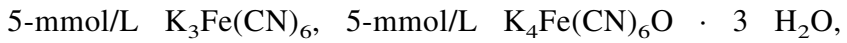
2-mmol/L magnesium chloride, and $0.01 \%$ sodium deoxycholate, ${ }^{11}$ was added. The cells were then incubated at $37^{\circ} \mathrm{C}$ and protected from light for 16 hours.

\section{Ligation of the Left Coronary Artery and Transplantation of MSCs}

Male Lewis rats (250-300 g) were used in this study as recipient animals. The animals were anesthetized with isoflurane (MTC Pharmaceuticals, Cambridge, Ontario, Canada), intubated, and mechanically ventilated at 80 breaths/min. A left anterolateral thoracotomy was performed under sterile conditions, and the left coronary was ligated approximately 1 to $2 \mathrm{~mm}$ from its origin with a 6-0 Prolene suture (Ethicon, Inc, Somerville, NJ). The ischemic myocardial segment rapidly became pale and hypocontractile. Mouse MSCs $\left(3 \times 10^{6}\right.$ cells suspended in 150 $\mu \mathrm{L}$ Dulbecco Modified Eagle Medium) were injected directly into the peri-ischemic region of the myocardium with a 28 gauge insulin syringe 15 minutes after ligation of the left coronary artery for animals in the study group. An equal volume of culture medium was injected into the control animals. Hemostasis was achieved with a 7-0 Prolene purse-string suture around the puncture site.

\section{Echocardiography}

Transthoracic echocardiography was performed on all animals at 4 weeks after coronary ligation and cell implantation. The echocardiographer was blinded to the experimental groups, and echocardiograms were obtained with a commercially available echocardiography system (SONO 5500, Hewlett-Packard) equipped with a $7.5-\mathrm{MHz}$ transducer (Hewlett-Packard Company, Palo Alto, Calif). ${ }^{12}$ With isoflurane anesthesia as mentioned previously, the heart was first imaged in the 2-dimensional parasternal long-axis view of the LV. Measurements of maximal LV long-axis lengths (L) and endocardial area tracings (a) with the leading edge method ${ }^{13}$ were performed from digital images captured on cineloops. LV end-diastolic volume 
(LVEDV) and LV end-systolic volume (LVESV) were calculated by the single-plane area-length method ${ }^{14}$ as $8 \times \mathrm{a}^{2} /(3 \times$ $3.14 \times \mathrm{L})$. $\mathrm{LV}$ ejection fraction $(\mathrm{LVEF})$ was then inferred as (LVEDV - LVESV)/LVEDV. M-mode images were obtained at the level of papillary muscles of the mitral valves. Enddiastolic and end-systolic diameters of the $\mathrm{LV}\left(\mathrm{LVED}_{\mathrm{d}}\right.$ and $\mathrm{LVED}_{\mathrm{s}}$ ) were determined. LV fractional shortening (LVFS) was inferred as $\left(\mathrm{LVED}_{\mathrm{d}}-\mathrm{LVED}_{\mathrm{s}}\right) / \mathrm{LVED}_{\mathrm{d}}$.

\section{Tissue Processing and Staining for $\boldsymbol{\beta}$-galactosidase Activity}

Animals were killed 1 day after the final echocardiogram (4 weeks after transplantation). The hearts were collected and rinsed with phosphate-buffered saline solution and perfusion fixed in $2 \%$ paraformaldehyde in phosphate-buffered saline solution. Staining for $\beta$-galactosidase activity was performed as described previously, but with the addition of $0.02 \%$ of Nonidet P-40 (Sigma Laboratories, St Louis, Mo) and 0.01\% deoxycholate to the staining solution. ${ }^{10}$ After Xgal staining, the hearts were sectioned on the short axis and embedded in paraffin.

\section{Histologic and Immunohistochemical Examination}

Heart sections $5 \mu \mathrm{m}$ in thickness were processed for hematoxylin and eosin staining, picrosirius red staining, and immunohistochemical staining. Immunohistochemical staining was done for anti- $\alpha$-smooth muscle actin (Sigma Laboratories), troponin IC (Santa-Cruz Biotechnology Inc, Santa Cruz, Calif), sarcomeric myosin heavy chain molecules with MF 20 (Developmental Studies Hybridoma Bank, developed under the auspices of the National Institute for Child Health and Development and maintained by the University of Iowa, Department of Biological Sciences, Iowa City, Iowa). Briefly, after deparaffinization, sections were placed in boiled citrate buffer ( $\mathrm{pH} \mathrm{6.0)}$. After blocking in normal serum, sections were treated with the respective monoclonal antibodies overnight and with secondary antibodies the next day. Diaminobenzidine was then used as a chromogen for light microscopy. Counterstaining of sections with hematoxylin and eosin was also performed. Cells derived from the implanted MSCs were identified by their blue nuclei ( $\beta$-galactosidase labeled) under Olympus light microscopy (BX-FLA; Olympus, Tokyo, Japan).

\section{Morphometric Analysis}

Paraffinized cross-sections of the LV at the level of the papillary muscles were stained with picrosirius red, and morphometric analysis was performed with a computerized surface determination method (Image Pro Analyzer; Media Cybernetics, Inc, Silver Spring, Md) to determine infarct size and thickness. Five histologic sections were obtained from each heart, and the data obtained were averaged. Calculations were based upon formulas validated in a rat infarct model described by Sandmann and coworkers. $^{13}$

\section{Statistical Analysis}

All data are reported as mean \pm SD. Comparisons between groups were conducted with the Student unpaired $t$ test.

\section{Results}

\section{MSC Culture}

MSCs proliferated in the culture medium, adhered to the bottom of the culture dish, and developed spindle-shaped morphology. After 3 to 4 passages, the initial 250 to 500 cells that had adhered to the culture dish expanded to more than 25 million cells. MSCs were transfected with replication-defective retrovirus carrying the $l a c Z$ reporter gene to trace their fate after transplantation. In vitro $\beta$-galactosidase staining demonstrated that transfection efficiency was nearly $100 \%$.

\section{Mortality}

Early mortality was the highest $(29.4 \%, 10 / 34)$ in groups I and II, which had undergone left coronary artery ligation, with 4 of the remaining 24 animals dying in the late postoperative period before the completion echocardiography could be performed. Thus groups I and II had sample sizes of 10 each for complete follow-up data. Mortalities in the immunologic control groups IIIA and IIIB, which had undergone fibroblast transplants with and without coronary ligation, were $10 \%$ (1/10) in each. There were no deaths $(0 / 5)$ in group IV, which had undergone sham surgery. The differences in mortality among these groups were, however, statistically not significant.

\section{Histologic and Immunochemical Assessment of Engrafted Cells}

Gross examination of all hearts in the study group (group I) revealed selective, localized blue discoloration of the Xgal stain near areas of infarcted myocardium, suggesting the presence of labeled cells (Figure 1, A). This was in contrast to the gross specimens of the control group (group II), which did not demonstrate any blue areas on gross examination.

Histologic examination of serial LV cross-sections confirmed that the blue discoloration of the myocardium visualized in the gross specimens was indeed due to the presence of $\beta$-galactosidase-positive cells (Figure 1, $B$, $C$, and $D$ ). MSCs were scattered throughout the LV myocardium and were found in all layers; however, cells were noted to cluster in the subendocardial regions of the peri-infarct zone. Some cells in this area acquired a phenotypic appearance similar to that of host cardiomyocytes (Figure 1, $C$ and $D$ ). Many of the surviving cells stained positively for the cardiomyocyte-specific protein troponin IC (Figure $1, E$ ). Few $\beta$-galactosidase-positive cells were found in the fibrous scar; however, those that were present in the scar tissue had a fibroblastlike appearance. 

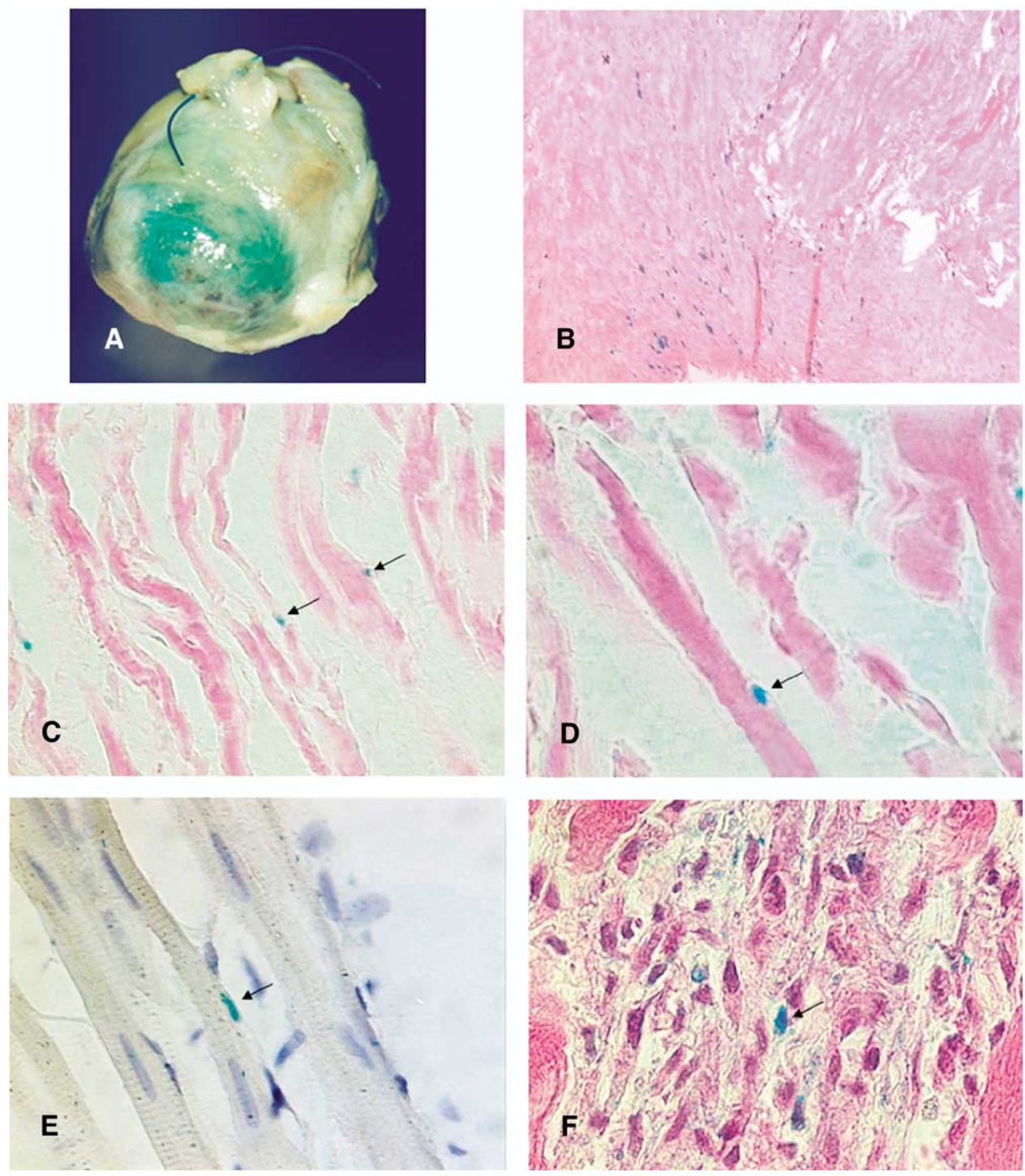

Figure 1. Gross heart specimen and phenotypic changes of MSCs. Hearts were harvested at 4 weeks after cell injection (MSC group, I) or culture medium injection (control group, II). Hearts were then stained for b-gal activity. Intense blue discoloration was seen on infarct and peri-infarct areas of heart in MSC group (A). Hematoxylin and eosin staining is shown at low power $(B, 40 \times)$ and eosinonly staining is shown at high power (C, 200X, and D, $400 \times$ ) of the peri-infarct zones of myocardium. Note $\beta$-galactosidase-positive cells (arrows) in peri-infarcted myocardium (C and D) are more elongated and phenotypically resemble surrounding host cardiomyocytes. Immunostaining was done for cardiomyocyte-specific contractile protein troponin IC (arrow in E, $400 \times$ ). In group III, histologic examination of LV cross-sections after injection of lacZ labeled mouse skin fibroblasts (arrow) showed extensive cellular infiltration within 1 day, particularly in subgroup IIIA with associated myocardial ischemic injury. However, in both subgroups with (IIIA) and without (IIIB) coronary ligations, only few remaining surviving labeled xenogeneic fibroblasts were found on day 4 after implantation ( $F$, hematoxylin and eosin, 40X).
Immunologic Control Groups (Groups IIIA and IIIB)

Animals in this group were subjected to direct intramyocardial injection of an identically labeled mature adult cell line (mouse skin fibroblasts), with or without coronary artery ligation, and were killed serially $(0,1,2,4$, and 7 days) in a 1-week period. Histologic examination of LV cross-sections showed extensive cellular infiltration within 1 day, particularly in group IIIA animals with myocardial ischemic injury from coronary ligation, with rapid loss of labeled implanted cells. We failed to detect surviving fibroblasts beyond 4 days in both subgroups IIIA (Figure 1, $F$ ) and IIIB.

\section{In Vivo Assessment of Cardiac Function}

LVEF and LVFS were used as indices of LV performance. Both parameters were clearly abnormal in both study (group I) and control (group II) groups; however, both were significantly better in animals that underwent MSC implantation at the time of left coronary artery ligation (LVEF $34.0 \% \pm 10.7 \%$ vs $19.9 \% \pm 10.0 \%, P=$ .007 , and LVFS $24.2 \% \pm 11.5 \%$ vs $14.3 \% \pm 5.51 \%, P=$ .02 ; Figure 2). Stroke volume was significantly better in the study group $(0.18 \pm 0.05 \mathrm{~mL}$ vs $0.12 \pm 0.05 \mathrm{~mL}, P$ $=.03$ ). End-diastolic volume was significantly lower in the MSC group, with a strong tendency toward lower 


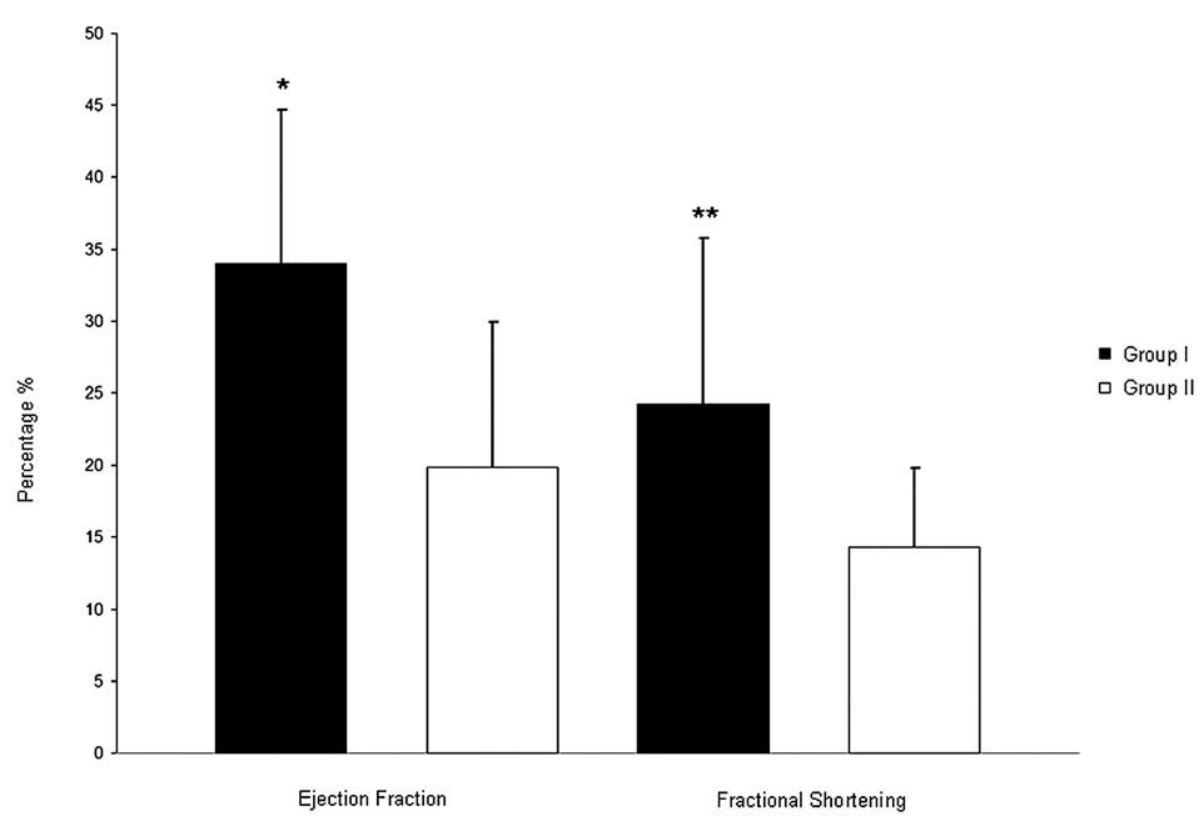

Figure 2. Indices of LV performance. Echocardiographic data 4 weeks after MSC (group I, black bars) or culture medium (group II, white bars) injection. Asterisk indicates $P$ $=.007$ for group I vs II; double asterisk indicates $P=.029$ for group I vs II.

end-systolic volumes as well (Figure 3). These same functional parameters were within normal values in the sham-operated group IV animals (LVEF 53.3\% $\pm 1.6 \%$, LVFS $31.9 \% \pm 4.1 \%$, LVESV $0.17 \pm 0.02 \mathrm{~mL}, \mathrm{LVEDV}$ $0.30 \pm 0.03 \mathrm{~mL})$.

Because groups IIIA and IIIB served as immunologic controls, they were only followed up until all implanted fibroblasts had been eliminated, which happened within a week. Thus echocardiographic studies corresponding to those for groups I and II, which were carried out at 4 weeks postimplantation, were not obtained.

\section{Morphometric Analysis}

Data from the LV morphometric analysis demonstrated that infarct size (expressed as a percentage of LV circumference) tended to be smaller in the MSC group $(32.1 \% \pm 13.2 \%$ vs $36.6 \% \pm 7.8 \%, P=.37)$. The infarcted portion of the $\mathrm{LV}$ also tended to be thicker in animals that received intramyocardial MSC injection at the time of left coronary artery ligation $(1.1 \pm 0.4 \mathrm{~mm}$ vs. $0.9 \pm 0.3 \mathrm{~mm}, P=.17$ ), although the difference did not reach statistical significance.

\section{Discussion}

The ability of xenotransplanted MSCs to survive the host immune reaction without the use of immunosuppression, particularly in the midst of the acute inflammatory microenvironment associated with a myocardial infarction, is intriguing. There is mounting evidence that MSCs are immune-privileged cells. Liechty and colleagues ${ }^{9}$ have reported that intraperitoneally transplanted human MSCs could engraft in fetal sheep, even after development of immunocompetence. These cells differentiated and integrated into host tissues, surviving as long as 13 months without immunosuppression. Caparrelli and associates $^{14}$ and Makkar and coworkers ${ }^{15}$ reported successful allogeneic MSC transplantation without the need for immunosuppressive medication in a swine model of myocardial infarction. These cells were shown to survive, differentiate, and contribute to functional improvement of the host myocardium. Additionally, our group observed that labeled mouse MSCs intravenously transplanted into the bone marrow of rats were later able to be recruited and engraft in damaged rat myocardium, forming a xenotransplant cardiac chimera. ${ }^{10}$

The presence of immunologic control groups (groups IIIA and IIIB) in this study strengthens the hypothesis that MSCs are uniquely immune-privileged cells.

After the intramyocardial injection in rats of labeled mature differentiated cells (skin fibroblasts) obtained from the same strain of donor mouse, rapid and massive inflammatory cellular infiltration was observed at the sites of implantation (Figure 2, F), with no surviving cells seen beyond 4 days. This suggests that, unlike the MSCs, the implanted mature cells were quickly and completely rejected by the xenogeneic recipients, as would be expected. We studied two immunologic control subgroups (groups IIIA and IIIB) to examine the possible effects of concomitant myocardial ischemic injury to the fate of these cells. We found that although myocardial injury induced more vigorous early inflammatory cellular responses, xenogeneic fibroblasts were eliminated within several days in both subgroups of recipients, in marked contrast to xenogeneic MSCs. 


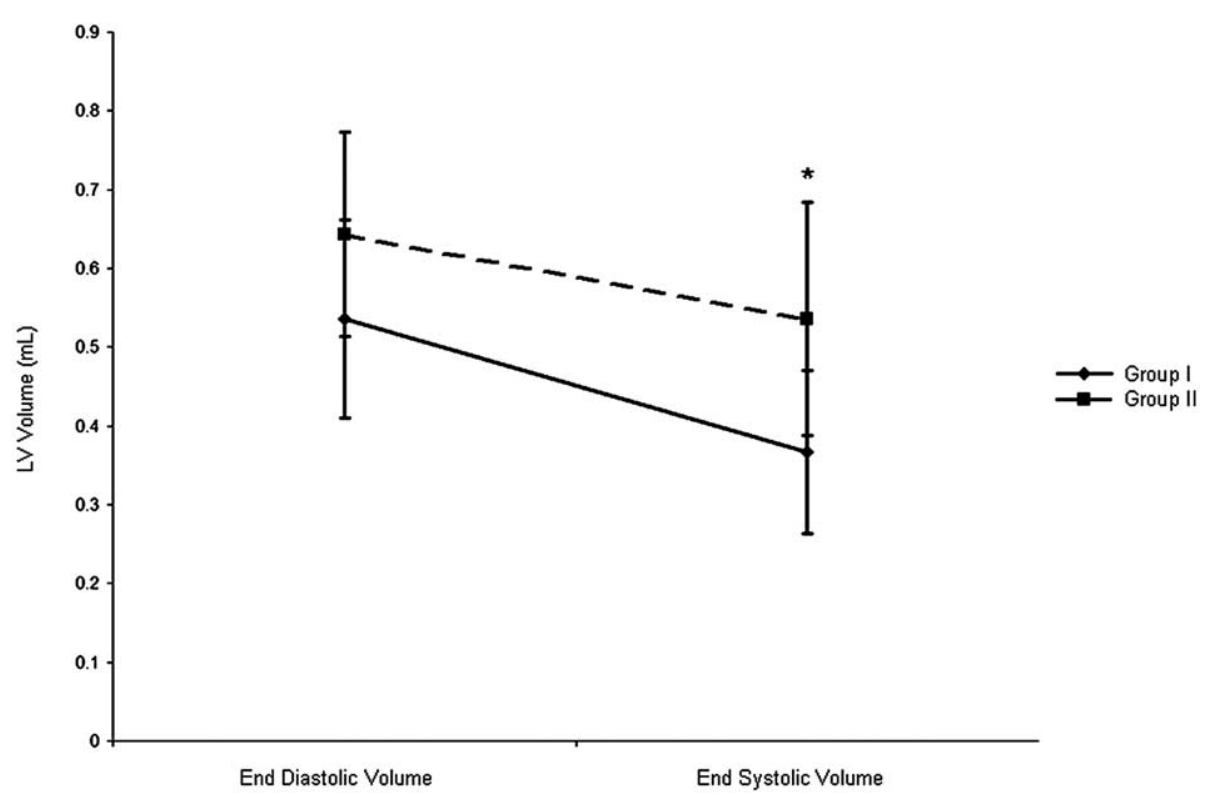

Figure 3. Components of stroke volume. Echocardiogram data performed at 4 weeks after MSC (group I, diamonds) or culture medium (group II, squares) injection comparing LVEDV and LVESV. Asterisk indicates $P=$ .009 for group I vs II.
Although we did not carry out in vitro immunologic assays to complement this study, our finding of MSC immune privilege is in fact consistent with observations made in many recent in vitro and in vivo studies. For example, it had been shown that MSCs cocultured with allogeneic dendric cells or peripheral lymphocytes suppress the proliferation of CD4 and CD8 cells. The signaling molecules for such suppression appear to include transforming growth factor $\beta 1$ and hepatocyte growth factor. ${ }^{8}$ MSCs may even induce suppressive cells from an already activated allogeneic $\mathrm{T}$ cell population. ${ }^{16}$ In vivo, the injection of allogeneic MSCs in baboons is tolerated without immunosuppression, ${ }^{17}$ and the induction of tolerance by MSCs has been reported to prolong skin graft survival as well. ${ }^{18}$ As mentioned previously, such MSC immune tolerance has also been reported in a human-to-sheep xenotransplant model. ${ }^{9}$ Our findings described here confirm these observations and further demonstrate that such xenogeneic donor cells can survive the inflammatory response associated with acute myocardial infarction, then differentiate and ameliorate ventricular dysfunction caused by the coronary occlusion.

Another finding of interest in this study is the in vivo differentiation of mouse MSCs inside the rat myocardium. There is strong evidence that MSCs receive signals from the microenvironment for their differentiation, known as milieudependent differentiation. The results obtained in this study indicate that such signals are not species specific. Our finding is consistent with those of Fukuhara and colleagues, ${ }^{19}$ in which in vitro coculture of mouse MSCs with neonatal rat cardiomyocytes successfully induced the former to undergo cardiomyocytic differentiation.

Although this is the first study to examine the functional contribution of transplanted xenogeneic MSCs, it is of interest to note that Min and coworkers ${ }^{20}$ reported improved cardiac function after implantation of cardiomyocytic progenitor cells derived from xenogeneic embryonic stem cells. In our study, assessment of in vivo cardiac function with transthoracic echocardiography demonstrated that LV function was clearly abnormal in both the study and control groups after the extensive myocardial insult produced by proximal left coronary artery ligation. However, animals that received MSC injection had significantly better indices of LV performance than did control animals. Our data suggest that hearts engrafted with MSCs had a tendency to dilate less than comparable control hearts, as demonstrated by the lower LVEDV. Contractile function also improved in the MSC group, with higher stroke volumes. Many studies of MSC therapy for infarcted myocardium have reported improved contractile function, ${ }^{7}$ although the mechanism of the improvement remains unclear. ${ }^{21}$ It has been suggested that functional improvement may be attributable to the improved contractile properties contributed by the neocardiomyocytes, by attenuation of remodeling and LV dilatation, and possibly by neoangiogenesis and improved performance of surviving myocytes. It is likely that the functional improvement is related to some combination of these factors, although this has yet to be definitively documented.

One of the major limitations in this report is lack of quantitative data on cell survival and differentiation. This important issue is under intensive study by us and others. In a mechanistic study, it is also desirable to identify more rigorously the cell population that exhibits such immune tolerance characteristics. Cell sorting is usually carried out by identifying and separating cell populations by their unique surface markers. Unfortunately, so far there has been no unanimous consensus on cell markers 
that are both sensitive and specific in identifying pluripotent stem cells. For example, it has been thought that hematopoietic stem cells are $\mathrm{CD} 34^{+}$, whereas marrow stromal stem cells are CD $34^{-}$. However, Sato and associates $^{22}$ showed recently that hematopoietic stem cells are originally derived from $\mathrm{CD} 34^{-}$fraction, and CD34 expression marks stem cell activation and mobilization. Nevertheless, our observation reported here does indicate that MSCs contain a population or populations of uniquely immunotolerant stem cells. It should be noted also that in many previous experimental and clinical studies such mixed population MSCs have been used without evidence of any harmful effects to the recipients.

In this study, we did not carry out karyotype analysis to address the possibility of a cell fusion phenomenon, ${ }^{23}$ which is a highly controversial issue at present, although transdifferentiation of adult stem cells has also been confirmed. ${ }^{24}$ If the labeled cardiomyocytes are the result of labeled MSC transdifferentiation, they should have euploid nuclei, but if they are the result of spontaneous cell fusion between a host cardiomyocyte and MSC, as some have suggested, they should be polyploid hybrid cells. Conflicting reports have been published for the frequency of cell fusion, which may ultimately depend on the type of stem cells and the experimental conditions used in these studies. Nevertheless, if the cell fusion is the predominant phenomenon, how such fused cells might contribute to improved ventricular function would be a perplexing question.

We believe that if our findings reported here can be further confirmed in other animal species, and with even longer follow-up to examine the possibility of chronic rejections, there could be profound clinical implications because of the possibility of using MSCs as "universal donor cells," which would require no immunosuppressive therapy for tissue regeneration. ${ }^{25}$ To observe immune tolerance, we chose a xenotransplant model for our experiments because it is immunologically more challenging than a model with allogeneic cells. It is important to emphasize that clinically, even if immunologically feasible, we would still favor the use of allotransplant cells as universal donor cells rather than using xenogeneic cells because of other risks associated with the latter in general, such as cross-species transmission of retroviral infections. However, the logistic advantages of using allogeneic universal donor cells rather than autologous cells, the feasibility of using donor cells from genetically normal individuals for recipients with genetic defects, and the potential use of young donor MSCs for senescent recipients whose autologous MSCs may be functionally compromised are all fascinating possibilities worthy of further exploration.

\section{References}

1. Johnstone B, Hering TM, Caplan AI, Goldberg VM, Yoo JU. In vitro chondrogenesis of bone marrow-derived mesenchymal progenitor cells. Exp Cell Res. 1998;238:265-72.

2. Ferrari G, Cusella-De Angelis G, Coletta M, Paolucci E, Stornaiuolo A, Cossu G, et al. Muscle regeneration by bone marrow-derived myogenic progenitors. Science. 1998;279:1528-30.

3. Petersen BE, Bowen WC, Patrene KD, Mars WM, Sullivan AK, Murase N, et al. Bone marrow as a potential source of hepatic oval cells. Science. 1999;284:1168-70.

4. Wakitani S, Saito T, Caplan AI. Myogenic cells derived from rat bone marrow mesenchymal stem cells exposed to 5-azacytidine. Muscle Nerve. 1995;18:1417-29.

5. Makino S, Fukuda K, Miyoshi S, Konishi F, Kodama H, Pan J, et al. Cardiomyocytes can be generated from marrow stromal cells in vitro. J Clin Invest. 1999;103:697-705.

6. Wang JS, Shum-Tim D, Galipeau J, Chedrawy E, Eliopoulos N, Chiu RC. Marrow stromal cells for cellular cardiomyoplasty: feasibility and potential clinical advantages. J Thorac Cardiovasc Surg. 2000;120: 999-1006.

7. Orlic D, Kajstura J, Chimenti S, Bodine DM, Leri A, Anversa P. Bone marrow cells regenerate infarcted myocardium. Nature. 2001;410: 701-5.

8. Di Nicola M, Carlo-Stella C, Magni M, Milanesi M, Longoni PD, Matteucci P, et al. Human bone marrow stromal cells suppress Tlymphocyte proliferation induced by cellular or nonspecific mitogenic stimuli. Blood. 2002;99:3838-43.

9. Liechty KW, MacKenzie TC, Shaaban AF, Radu A, Moseley AM, Deans R, et al. Human mesenchymal stem cells engraft and demonstrate site-specific differentiation after in utero transplantation in sheep. Nat Med. 2000;6:1282-6.

10. Saito T, Kuang JQ, Bittira B, Al-Khaldi A, Chiu RCJ. Xenotransplant cardiac chimera: immune tolerance of adult stem cells. Ann Thorac Surg. 2002;74:19-24.

11. Wang JS, Shum-Tim D, Chedrawy E, Chiu RC. The coronary delivery of marrow stromal cells for myocardial regeneration: pathophysiologic and therapeutic implications. J Thorac Cardiovasc Surg. 2001;122: 699-705.

12. Saito T, Kuang JQ, Lin CC, Chiu RC. Transcoronary implantation of bone marrow stromal cells ameliorates cardiac function after myocardial infarction. J Thorac Cardiovasc Surg. 2003;126:114-23.

13. Sandmann S, Spitznagel H, Chung O, Xia QG, Illner S, Janichen G, et al. Effects of the calcium channel antagonist mibefradil on haemodynamic and morphological parameters in myocardial infarctioninduced cardiac failure in rats. Cardiovasc Res. 1998;39:339-50.

14. Caparrelli DJ, Cattaneo SM, Shake JG, Flynn EC, Meyers K, Baumgartner WA, et al. Cellular myoplasty with mesenchymal stem cells results in improved cardiac performance in a swine model of myocardial infarction. Circulation. 2001;104(suppl):II599.

15. Makkar RR, Price M, Lill M. Multilineage differentiation of transplanted allogenic mesenchymal stem cells in a porcine model of recent myocardial infarction improves left ventricular function. Circulation. 2002;106(suppl):II34.

16. McIntosh K, Bartholomew A. Stromal cell modulation of the immune system: a potential role for mesenchymal stem cells. Graft. 2000;3: 324-8.

17. Devine SM, Bartholomew AM, Mahmud N, Nelson M, Patil S, Hardy W, et al. Mesenchymal stem cells are capable of homing to the bone marrow of non-human primates following systemic infusion. Exp Hematol. 2001;29:244-55.

18. Bartholomew A, Sturgeon C, Siatskas M, Ferrer K, McIntosh K, Patil $\mathrm{S}$, et al. Mesenchymal stem cells suppress lymphocyte proliferation in vitro and prolong skin graft survival in vivo. Exp Hematol. 2002;30: 42-8.

19. Fukuhara S, Tomita S, Yamashiro S, Morisaki T, Yutani C, Kitamura $\mathrm{S}$, et al. Direct cell-cell interaction of cardiomyocytes is key for bone marrow stromal cells to go into cardiac lineage in vitro. $J$ Thorac Cardiovasc Surg. 2003;125:1470-80.

20. Min JY, Yang Y, Sullivan MF, Ke Q, Converso KL, Chen Y, et al. Long-term improvement of cardiac function in rats after infarction by 
transplantation of embryonic stem cells. J Thorac Cardiovasc Surg. 2003;125:361-9.

21. Chiu RC. Therapeutic cardiac angiogenesis and myogenesis: the promises and challenges on a new frontier [editorial]. J Thorac Cardiovasc Surg. 2001;122:851-2.

22. Sata M, Saiura A, Kunisato A, Tojo A, Okada S, Tokuhisa T, et al. Hematopoietic stem cells differentiate into vascular cells that participate in the pathogenesis of atherosclerosis. Nat Med. 2002;8: 403-9.
23. Terada N, Hamazaki T, Oka M, Hoki M, Mastalerz DM, Nakano Y, et al. Bone marrow cells adopt the phenotype of other cells by spontaneous cell fusion. Nature. 2002;416:542-5.

24. Wurmser AE, Nakashima K, Summers RG, Toni N, D’Amour KA, Lie DC, et al. Cell fusion-independent differentiation of neural stem cells to the endothelial lineage. Nature. 2004;430:350-6.

25. Chiu RC. "Stealth immune tolerance" in stem cell transplantation: potential for "universal donors" in myocardial regenerative therapy. J Heart Lung Transplant. 2005;24:511-6. 